\title{
Could VEGF-D level have a role in clinical risk scoring, estimation of thrombus burden, and treatment in acute pulmonary thromboembolism?
}

\author{
Buğra Kerget ${ }^{1}$, Dursun Erol Afşin ${ }^{2}$, Alperen Aksakal ${ }^{2}$, Ferhan Kerget ${ }^{2}$, Seda Aşkın², Elif \\ Yilmazel Ucar ${ }^{2}$, and Leyla Sağlam ${ }^{1}$ \\ ${ }^{1}$ Ataturk Universitesi \\ ${ }^{2}$ Affiliation not available
}

May 5, 2021

\begin{abstract}
Objective: Pulmonary embolism (PE) is usually a complication of deep vein thrombosis and is an important cause of mortality and morbidity. Vascular endothelial growth factor D (VEGF-D) is a secretory protein that plays a role in the remodeling of blood vessels and the lymphatic system. This study aimed to determine the relationship between VEGF-D level and clinical risk scoring in patients with PE. Methods: The study included 117 patients admitted for PE that were divided into 4 groups: high-risk patients $(\mathrm{n}=35)$, high-intermediate-risk patients $(\mathrm{n}=30)$, low-intermediate-risk patients $(\mathrm{n}=24)$, and low-risk patients $(\mathrm{n}=28)$. Plasma VEGF-D was measured from peripheral venous blood samples (5 cc) using a commercial enzyme-linked immunosorbent assay (ELISA) kit. Pulmonary Artery Obstruction Index (PAOI) was calculated from CT angiography imaging. Results: VEGF-D levels in the low-risk PE group differed significantly from those in the high-intermediate and high-risk groups ( $p=0.001$ for both) but not from that in the low-intermediate-risk PE group $(p=0.155)$. There was no significant difference in troponin-I and NT-proBNP levels between the high-intermediate-risk and high-risk PE patients, whereas VEGF-D levels differed significantly $(\mathrm{p}=0.134, \mathrm{p}=0.146, \mathrm{p}=0.016)$. VEGF-D level was moderately correlated with mean pulmonary artery pressure and PAOI $(\mathrm{r}=0.481, \mathrm{p}=0.01 ; \mathrm{r}=0.404, \mathrm{p}=0.01)$. In ROC curve analysis, a cut-off of $370.1 \mathrm{pg} / \mathrm{ml}$ for VEGF-D had $91.4 \%$ sensitivity and $67.4 \%$ specificity in the differentiation of high-intermediate-risk and high-risk PE patients. Conclusion: This study showed that plasma VEGF-D level was more reliable than troponin-I and NT-proBNP in clinical risk scoring and demonstrating thrombus burden. VEGF-D can be used as a biomarker in clinical risk scoring and estimation of thrombus burden in patients with acute PE.
\end{abstract}

\section{Hosted file}

main documnent_EN200307.pdf available at https://authorea.com/users/387698/articles/520864could-vegf-d-level-have-a-role-in-clinical-risk-scoring-estimation-of-thrombus-burdenand-treatment-in-acute-pulmonary-thromboembolism

\section{Hosted file}

Table 1.pdf available at https://authorea.com/users/387698/articles/520864-could-vegf-dlevel-have-a-role-in-clinical-risk-scoring-estimation-of-thrombus-burden-and-treatmentin-acute-pulmonary-thromboembolism

\section{Hosted file}

Figure 1.pdf available at https://authorea.com/users/387698/articles/520864-could-vegf-dlevel-have-a-role-in-clinical-risk-scoring-estimation-of-thrombus-burden-and-treatment- 
in-acute-pulmonary-thromboembolism 